\title{
Influence of Climate Change and Anthropogenic Activities on Groundwater Level in the Northern Huangqihai Basin, China
}

Jing Jin ( $\nabla_{\text {jinjingmwr@163.com ) }}$

Institute of Water Resources for Pastoral Area,MWR https://orcid.org/0000-0001-6166-1804

\section{Zihe Wang}

Institute of Water Resources for Pastroal Area,MWR

Yiping Zhao

Institute of Water Resources for Pastoral Area,MWR

Huijun Ding

Geological Environment Monitoring Insititute of Inner Mongolia

Yufei Chen

Housing and Urban Rual Development Bureau of Saihan District,Hohht

\section{Research Article}

Keywords: Variation in groundwater level, Quantitative assessment, Climate change, Anthropogenic activities, Northern Huangqihai basin.

Posted Date: August 4th, 2021

DOI: https://doi.org/10.21203/rs.3.rs-523965/v1

License: (c) (i) This work is licensed under a Creative Commons Attribution 4.0 International License. Read Full License 


\title{
Influence of climate change and anthropogenic activities on groundwater level in the northern Huangqihai basin, China
}

(1)

(1)

\author{
1 Yinshanbeilu National Field Research Station of Desert Steppe Eco-hydrological System,
}

China Institute of Water Resources and Hydropower Research, Beijing 100038, China

2 Institute of Water Resources for Pastoral Area, MWR, Hohhot 010020, China;

3 Geological Environment Monitoring Institute of Inner Mongolia, Hohhot 010020, China

4 Housing and Urban-Rural Development Bureau of Saihan District, Hohhot 010020, China

*Corresponding author: jinjingmwr@163.com (Jing Jin)

Abstract: The variation in the groundwater level, which is an indicative factor that can reflect changes in both groundwater level and groundwater quantity, was selected as the factor to be analyzed. Rainfall and groundwater exploitation were chosen as the representative factors of climate change and anthropogenic activities, respectively. By applying the elastic coefficient method and other mathematical statistical methods, the influence of climate change and anthropogenic activities on groundwater was analyzed qualitatively and quantitatively. The northern Huangqihai basin was chosen as the study area. The rainfall in the study area showed an increasing trend from 1996-2020, while most variations in groundwater level were negative. This result indicated that the positive influence of rainfall on the variation in the groundwater level in the study area was not enough to offset the negative influence of groundwater exploitation. The correlation between anthropogenic activities and variations in the groundwater level was lower in wet years than in normal years but the highest in dry years. Based on the comparative method of the slope changing ratio of cumulative quantity and the elastic coefficient method, it was determined that the contribution rate of climate change to the variation in groundwater level was $22.08 \%$ and that of human activities was $77.92 \%$. Thus, the sustainable development of the groundwater environment can be realized by positively guiding anthropogenic activities and minimizing negative influences.

Keywords: Variation in groundwater level; Quantitative assessment; Climate change; Anthropogenic activities; Northern Huangqihai basin. 


\section{Introduction}

Groundwater is an important resource for human survival and development, especially in the arid and semiarid areas of Northwest China, where water resources are scarce and the ecological environment is sensitive and fragile (Wang et al. 2020; Wu et al. 2019, 2020; Ren et al. 2021; Wei et al. 2021). In the past 100 years, the increase in temperature and rainfall variability, as well as changes in natural environment, has changed the quantity, quality and spatiotemporal distribution of groundwater resources ( $\mathrm{Li}$ et al., 2019; Cui et al, 2020). Simultaneously, the interference of anthropogenic activities on groundwater has increased (Acharyya and Achiransu 2014; Yihdego et al., 2017b; Li et al., 2018b; He and Wu 2019a; He and Li 2020; Khan et al., 2020), which has changed the evolution of the groundwater environment from a single naturally driven model to a dual naturally-artificially driven mode (Wang et al., 2006). Quantitative research on the influence of climate change and anthropogenic activities on groundwater is a hot but challenging topic in the field of hydrology and water resources (Wang et al., 2011; Li 2014; Li et al., 2018b), and is of great significance for protecting groundwater resources and promoting the sustainable development of the groundwater environment.

Previous studies on the influence of climate change and anthropogenic activities on the groundwater level have mainly focused on qualitative analyses (Liao et al., 2014; Shi et al., 2014; Jin et al., 2020), while the quantitative analyses in this field have been based on mathematical statistics methods and simulation model (Su et al. 2020). Some researchers (Hotta et al., 2010; Kearns et al., 2015; Wilopo et al., 2021) have analyzed the influence of urbanization and groundwater exploitation on groundwater level by using mathematical statistical methods, such as correlation analysis and wavelet coherence analysis. Malaka et al. (2021) considered groundwater exploitation as the dominant factor in groundwater level change based on mathematical statistical methods. By applying multivariate linear regression analysis, Yihdego et al. (2017a) concluded that the rise in the groundwater level in coastal areas of New South Wales was caused by a long-term cumulative land-use change. Wei et al. (2016) used the bidirectional regression mutation analysis method to analyze the response relationship between a decrease in the groundwater level and the irrigation area in the Jiansanjiang region of Heilongjiang Province. The Mann-Kendall ( $M-K)$ test is commonly utilized to evaluate the influence of climate change and anthropogenic activities on changes in groundwater depth (Zhu et al., 2017; Cui et al., 2020). Gemitzi and Stefanopoulos (2011) applied the autoregressive integrated moving average 
(ARIMA) model based on abundant basic data to analyze the influence of irrigation and rainfall on the groundwater level. He and $\mathrm{Wu}$ (2019b) and He et al. (2020) investigated the relationship between land use/land cover and groundwater quality, and concluded that the change in land use/land cover was an indicator representing integrated human activities and that its impact on groundwater can be quantified using the curved streamline searchlight shaped model. Fei et al. (2009) considered that groundwater exploitation played an important role in the decrease in groundwater level through correlation analysis.

From the perspective of hydrogeology, the variation in groundwater level is an intuitive indicator of not only the change in groundwater level but also the change in groundwater storage, as shown in Eq. (1) (China Geological Survey 2018).

$$
\Delta Q=\mu \times F \times \frac{\bar{W}}{\Delta t}
$$

where $\Delta Q$ is the variation in groundwater storage $\left(\mathrm{m}^{3}\right), \mu$ is the specific yield of phreatic water, $F$ is the area of the phreatic aquifer $\left(\mathrm{m}^{2}\right), \bar{W}$ is the average variation in groundwater level $(\mathrm{m})$, and $\Delta t$ is time (a).

Therefore, the variation in groundwater level, which can directly reflect the changes in groundwater level and groundwater storage, was selected as the analysis factor of groundwater in this study. Rainfall, which is important to groundwater recharge, was selected as the factor of climate change that influences groundwater, and groundwater exploitation was chosen as the factor of anthropogenic activities that directly influences groundwater. First, the characteristics of annual rainfall, groundwater exploitation and the variation in groundwater level from 1996-2020 were qualitatively analyzed. Second, the influences of climate change and anthropogenic activities on groundwater were quantitatively analyzed by using the comparative method of the slope changing ratio and the elastic coefficient method. This study is very meaningful for the protection and management of groundwater.

\section{Materials and Methods}

\section{Study area}

The northern Huangqihai basin $\left(113^{\circ} 2^{\prime}-113^{\circ} 28^{\prime} \mathrm{E}, 40^{\circ} 43^{\prime}-41^{\circ} 3^{\prime} \mathrm{N}\right)$, in Right Chahaer County and the Jinning District of Wulanchabu city in Inner Mongolia, China, is located in the middle of the northern farming-pastoral ecotone and covers nearly $521 \mathrm{~km}^{2}$ in area (Fig. 1). The study area is an important ecological barrier in the northern Beijing-Tianjin-Hebei region, where water resources are rare and the ecological environment is sensitive and fragile. The development of the regional social 
economy is highly dependent on groundwater and mainly exploits a shallow aquifer, which is the Quaternary aquifer that consists of sand and gravel of varying sizes. The basin is surrounded by mountains on three sides, and the terrain around Huangqihai Lake is relatively low. Thus, groundwater generally flows from the surrounding area to Huangqihai Lake. There is a thick clay layer under the Quaternary aquifer, which results in a weak hydraulic relationship between the Quaternary aquifer and the deeper aquifer.

The recharge sources of groundwater are rainfall infiltration and groundwater lateral inflow, and rainfall infiltration accounts for approximately $60 \%$ of the total recharge. The discharge sources are exploitation, evaporation and discharge into the lake, and groundwater exploitation accounts for approximately $45 \%$ of the total discharge. The depth of groundwater in most areas is deeper than $5 \mathrm{~m}$, exceeding the limit evaporation depth. According to Aver'yanov's evaporation equations, evaporation has a slight influence on the groundwater level. Therefore, rainfall and groundwater exploitation were selected as the factors of climate change and anthropogenic activities, respectively.

\section{Data requirements and preparation}

Groundwater level variation, groundwater exploitation and rainfall data were applied to research the influence of climate change and anthropogenic activities.

Groundwater monitoring in the study area started in the 1990s and has been gradually strengthened. The distribution of the monitoring wells was shown in Fig. 1. The groundwater level monitoring data (1996-2020) were collected from the Geological Environment Monitoring Institute of Inner Mongolia, and then these data were calculated. The annual variation $(W)$ in groundwater level was the groundwater level in December minus the groundwater level in January, and the annual average of the groundwater level $(H)$ was the average of the groundwater level for 12 months of the year.

Data on the quantity of groundwater exploitation $\left(Q_{G E}\right)$ from 2011-2020 were derived from the Water Resources Bulletin of Right Chahar County. The data from 1998-2010 were calculated by the different proportions of total groundwater exploitation of Wulanchabu city in wet, normal and dry years. There were no available data from 1996-1997.

To ensure consistency with groundwater level data, the annual rainfall and monthly rainfall during the period from 1996-2020 were obtained from the China Meteorological Data Network 
(http://data.cma.cn). Because the geographic position of the study area is near to Jining District, the meteorological station of Jining District was selected to reflect the climate change in the study area.

\section{Methods}

Based on an analysis of the characteristics of annual rainfall, $Q_{G E}$ and $W$ from 1996 to 2020, the influence of climate change and anthropogenic activities on groundwater level was qualitatively researched. The $M-K$ mutation test and cumulative anomaly method were used to determine the mutation years of annual rainfall and $W$, and the contribution rates of climate change and anthropogenic activities to groundwater level were calculated by using the comparative method of the slope changing ratio of cumulative quantity and the elastic coefficient method.

\section{$M-K$ trend test}

The $M-K$ trend test is a rank nonparametric test method that is recommended by the World Meteorological Organization (Wang et al., 2019; Fang et al.,2019). This test was conducted to analyze the trend of annual rainfall in the study area from 1996 to 2020.

If the statistical value $(Z)$ was greater than zero, it indicated that the trend of annual rainfall in the period was increasing, whereas if $Z$ was less than zero, it indicated that the trend of annual rainfall was decreasing. Given the level of significance $(\alpha)$, if the absolute value of $Z(|Z|)$ was greater than $Z_{1-\alpha / 2}$, the trend was significant; if $|Z|$ was less than $Z_{1-\alpha / 2}$, the trend was insignificant. When $\alpha$ was 0.05 , the threshold corresponding to the level of significance was 1.96 .

\section{M-K mutation test}

The $M-K$ mutation test is a simple and effective nonparametric statistical method to recognize mutations, it is widely utilized in meteorology, hydrology and other research fields (Zhu et al., 2017; Liu et al., 2019a).

By using the $M-K$ mutation test, $U F$ and $U B$ curves were obtained. When a given level of significance was exceeded, it indicated that the trend of the sequence was significant. When $\alpha$ was 0.05 , the threshold corresponding to the level of significance was 1.96. If the intersection of the $U F$ and $U B$ curves was between the significant horizontal lines, the time corresponding to the intersection was considered as the time of the mutation (Cui et al., 2020).

\section{Cumulative anomaly method}

The cumulative anomaly method is a nonlinear statistical method that can directly reflect changes in the trends of discrete data. This method can directly reflect the changes in climate and hydrological 
data in different periods and stages and then directly recognize the mutation year (Zhu et al., 2017; Liu et al., 2019b). The cumulative anomaly value $\left(I_{L P}\right)$ of the analysis factor $X$ at time t was calculated by using Eq. (2).

$$
I_{L P}=\sum_{i=1}^{n}\left(x_{i}-\bar{x}\right)
$$

where $x_{i}$ is the value of the analysis factor $X$, i.e. rainfall and $W$, in the $i$ th year $(i=1,2, \ldots, \mathrm{n})$ and $\bar{x}$ is the average of $X$.

\section{Comparative method of the slope changing ratio of cumulative quantity}

The comparative method of the slope changing ratio of cumulative quantity (Wang et al, 2012; Zhu et al., 2017; Zhao et al., 2019) was applied to calculate the contribution rates of climate change and anthropogenic activities to groundwater. The method was not influenced by subjective weight assignment, and the quantitative results were objective and reasonable.

Because the values of $W$ were either positive or negative, normalization needed to be performed according to Eq. (3).

$$
y_{i}=\frac{w_{i}-w_{\min }}{w_{\max }-w_{\min }}
$$

where $w_{i}$ is the value of $W$ in the $i$ th year $(i=1,2, \ldots, \mathrm{n})$ and $y_{i}$ is the normalized value of $w_{i}$.

Based on this finding, the linear slopes of the relationship between $y_{i}$ and the years before and after the mutation were determined, i.e., $S_{W b}$ and $S_{W a}$, respectively, and then the slope change rate of cumulative values of the groundwater level variation $\left(R_{S W}\right)$ was obtained by using Eq. (4).

$$
R_{S W}=\frac{\left(S_{W a}-S_{W b}\right)}{S_{W b}} \times 100 \%
$$

Similarly, the slope change rate of cumulative values of the annual rainfall $\left(R_{S R}\right)$ was obtained by using Eq. (5).

$$
R_{S R}=\frac{\left(S_{R a}-S_{R b}\right)}{S_{R b}} \times 100 \%
$$

If $R_{S W}$ and $R_{S R}$ were positive, the slopes increased after the mutation; otherwise, the slope decreased after the mutation. The contribution rate $\left(C_{R}\right)$ of the annual rainfall to $W$ was defined as:

$$
C_{R}=\frac{R_{S R}}{R_{S W}} \times 100 \%
$$

The contribution rate of groundwater exploitation $\left(C_{G E}\right)$ to $W$ was obtained according to Eq. (7).

$$
C_{G E}=1-C_{R}
$$




\section{Elastic coefficient method}

Based on previous research on the elastic coefficient of runoff to climate change (Guo 2016; Li 2016), the method was applied to quantitatively analyze the influence of climate change on groundwater level, and the median of the climate variable (Sankarasubramanian et al., 2001; Li et al., 2021) was adopted to estimate the elastic coefficient $\left(\varepsilon_{R}\right)$ of $W$ to annual rainfall.

$$
\varepsilon_{R}=\frac{W_{i}-\bar{W}}{R_{i}-\bar{R}} \times \frac{\bar{R}}{\bar{W}}
$$

where $W_{i}$ is the annual variation in groundwater level in the $i$ th year $(i=1,2, \ldots, \mathrm{n}), R_{i}$ is the annual rainfall in the $i$ th year, $\bar{W}$ is the average of $W_{i}$, and $\bar{R}$ is the average of $R_{i}$.

According to Eq. (9), the change in groundwater level variation after the mutation $\left(\Delta W_{a}\right)$ was calculated based on the elastic coefficient $\varepsilon_{R}$.

$$
\Delta W_{a}=\frac{\bar{R}_{a}-\bar{R}_{b}}{\bar{R}_{b}} \times \varepsilon_{R} \times \overline{W_{b}}
$$

where $\bar{R}_{a}$ is the average of the annual rainfall after the mutation, $\bar{R}_{b}$ is the average of the annual rainfall before the mutation, and $\overline{W_{b}}$ is the average of $W$ before the mutation.

The contribution rates of annual rainfall and groundwater exploitation were calculated by using Eqs. (10) and (11).

$$
\begin{gathered}
\mathrm{C}_{R}^{\prime}=\frac{\Delta W_{a}}{\overline{W_{a}}-\overline{W_{b}}} \times 100 \% \\
\mathrm{C}_{G E}^{\prime}=1-\mathrm{C}_{R}^{\prime}
\end{gathered}
$$

where $\overline{W_{a}}$ is the average of $W$ after the mutation.

\section{Results and Discussion}

\section{Variation characteristics of rainfall, $Q_{G E}$ and groundwater level}

The study area is in a semiarid continental climate zone and the average annual rainfall was $359.30 \mathrm{~mm}$ during the1996-2020 period. The monthly rainfall distribution was uneven (Fig. 2) and mainly concentrated from June to August. The rainfall during these three months accounted for $60 \%$ of the annual rainfall. The wet and dry years appeared alternately; the maximum annual rainfall was 547.7 $\mathrm{mm}$ in 2012 , while the minimum annual rainfall was $184.5 \mathrm{~mm}$ in 2009 . The extreme ratio $K$, which was calculated by dividing the maximum by the minimum, was 2.97 and indicated a large difference in annual rainfall between the wettest year and the driest year. According to the $M-K$ trend test, there was an increasing trend of the annual rainfall from 1996-2020 (Fig. 3), but the $Z$ value of the annual rainfall was 0.63 , less than $Z_{1-\alpha / 2}$, which indicated that the increasing trend of the annual rainfall from 
1996-2020 was not obvious. The characteristic values of the annual rainfall were calculated by the P-III curve of hydrological frequency (Table 1), and the amount of rainfall substantially varied by years.

The $Q_{G E}$ in the study area showed an upward trend from 1998 to 2016 (Fig. 3). The $Q_{G E}$ values were relatively low in 2003, 2004 and 2012, which was mainly due to a abundant rainfall and the decrease in groundwater consumption by agricultural irrigation. The regional water administrative departments strengthened the rational management of the groundwater quantity from 2017 to 2020, and the values of $Q_{G E}$ decreased year by year. The consumption of groundwater was different in different industries in the study area. The proportion rate of agricultural consumption in $Q_{G E}$ exceeded $50 \%$, domestic consumption had the second highest rate, and ecological demand for groundwater had the lowest rate.

The annual average of the groundwater level $(H)$ was selected to reflect the change in groundwater level in the whole year. As shown in Fig. 3, $H$ in the study area showed a decreasing trend overall due to unreasonable exploitation. $H$ decreased rapidly from 2011 to 2018 and increased slightly in the period from 2019-2020. The values of $W$ in the study area gradually changed from positive to negative for the period from 1996 to 2020 (Fig. 3), indicating a continuous decrease in the groundwater level. In 2011 , the value of $W$ was the maximum negative value, while the value of $Q_{G E}$ in the same year was the highest. After 2014, the values of $W$ generally increased, but the values of $W$ remained negative.

\section{Qualitative analysis of the influence of climate change and anthropogenic activities on groundwater}

The changes in annual rainfall, $Q_{G E}$ and $W$ in different years were compared. In the wet year of 2012, the annual rainfall was $547.7 \mathrm{~mm}$, which was the maximum rainfall in the period from 1996-2020; the $Q_{G E}$ value was only 0.3156 billion $\mathrm{m}^{3}$ in the same year, which was the minimum in this groundwater.

Over the whole period of 1996-2020, the annual rainfall in the study area showed an increasing trend, but the values of $W$ remained negative for many years, and $H$ showed a decreasing trend. The more rainfall there is, the more groundwater recharges. The higher $Q_{G E}$ there is, the more groundwater 
discharges. The contrasting characteristics of the annual rainfall and $W$ indicated that the positive influence of annual rainfall on groundwater level was weaker than the negative influence of groundwater exploitation. Due to excessive and unreasonable exploitation of groundwater in the study area for years, the groundwater level has continually decreased, and $W$ has been negative for a long time. The negative values of $W$ were reduced due to the decrease in $Q_{G E}$ from 2017 to 2020 . not be disregared. Hereafter, the influence of the two on groundwater was analyzed under different conditions.

Influence of annual rainfall on W under the same exploitation conditions

The $Q_{G E}$ values in 1999 and 2000 were 0.4276 billion $\mathrm{m}^{3}$ and 0.4214 billion $\mathrm{m}^{3}$, respectively, and the relative difference between them was less than $0.02 \%$; thus, the $Q_{G E}$ values in 1999 and 2000 were considered the same exploitation conditions. Similarly, the exploitation conditions in 2015 and 2016 were considered equivalent. The two identical exploitation conditions from 1999-2000 and 2015-2016, named conditions $A$ and $B$, respectively, were chosen to perform the following research (Table 2 and Fig. 4). under the same rainfall conditions. was abundant; the $Q_{G E}$ values were relatively low; and the $W$ values were positive. The $Q_{G E}$ value in 
2016 was higher than the $Q_{G E}$ values in 1998 and 2003, and the $W$ value in 2016 was lower than the $W$ values in the other two years.

Under condition $B^{\prime}, 1999,2000$ and 2014 were the normal years, and the rainfall was at the middle level. The negative values of $W$ decreased due to an increase in $Q_{G E}$. The $Q_{G E}$ values in the three normal years were larger than the $Q_{G E}$ values in the wet years. The value of $W$ was lower in the normal years due to an increase in $Q_{G E}$.

Under condition $C^{\prime}, 2001$ and 2006 were dry years; rainfall was the lowest; and the $Q_{G E}$ values in these two years were larger than the $Q_{G E}$ values in wet years. The negative values of $W$ decreased sharply due to an increase in $Q_{G E}$. Moreover, $W$ was more sensitive to the change in $Q_{G E}$ with the insufficient recharge of rainfall. Under the same rainfall conditions, the $Q_{G E}$ value in 2006 was $1.11 \%$ Pearson correlation analysis showed that there was a negative correlation between $Q_{G E}$ and $W$. larger than that in 2001, but the corresponding $W$ was $489.43 \%$ larger in 2006 than that in 2001.

In summary, $W$ decreased due to an increase in $Q_{G E}$ under the same rainfall conditions. The Accompanied by the decrease in annual rainfall, the correlation coefficient $r$ ' between $Q_{G E}$ and $W$ changed from -0.4690 to -1.000 at the level of significance $\alpha$ of 0.01 , which indicated that the influence of $Q_{G E}$ on $W$ increased with a decreasing in the rainfall recharge.

\section{Influence of rainfall and groundwater exploitation on $W$ in different months of the year}

Due to the lack of monthly groundwater exploitation data, the analysis was focused on the changes in monthly rainfall and monthly variation in groundwater level $\left(W_{m o n}\right)$, and then the influence of groundwater exploitation on groundwater level was reflected peripherally.

According to the groundwater flow field (Fig. 6), the monitoring wells of the groundwater level upstream, midstream and downstream (M069, M030 and M017; M034 and M033) were chosen to analyze the changes in $W_{m o n}$ in different months of the year. The distributions of the monthly rainfall under different rainfall conditions varied; thus, the analysis was performed under the three rainfall conditions, i.e., wet years, normal years and dry years.

It can be seen from Fig. 7 that $W_{\text {mon }}$ differed among the monitoring wells and varied by years. Overall, the $W_{m o n}$ values were low from January to April, and the $W_{m o n}$ value was mostly positive in April. These results were attributed to the lagging recharge from rainfall and the melting of ice and snow. Although the rainfall increased obviously in summer, the $W_{m o n}$ did not immediately change to 
positive values but remained negative, and some negative values of $W_{\text {mon }}$ decreased, such as the $W_{\text {mon }}$ values at M017, M034, and M030 in July 2003. The consumption by agriculture and industry was high, summer was the peak period of groundwater exploitation, and the negative influence of anthropogenic discharge on the groundwater level was greater than the positive influence of rainfall recharge. Based on a comparison among the changes in the $W_{\text {mon }}$ of the selected monitoring wells, the characteristics of the $W_{\text {mon }}$ upstream, midstream and downstream were similar, indicating that for the whole area, the influence of groundwater exploitation was greater than that of rainfall.

Determination of the time of the mutation

The first step of a quantitative assessment of the influence of climate change and anthropogenic activities on groundwater level was to determine the time of the mutation. The $M-K$ mutation test and cumulative anomaly method were employed in this study.

According to Fig. 8, the $U F$ and $U B$ curves of the annual rainfall and $W$ intersected in 2004 at a significance level of 0.05 (Fig. 8). In addition, the inflection point based on the cumulative anomaly curves of the annual rainfall and $W$ appeared in 2004 (Fig. 9). Therefore, the time of the mutation year was determined to be 2004; the period from1996-2004 was defined as the period before the mutation; and the period from 2005-2020 was defined as the period after the mutation.

Quantitative assessment of the influence of climate change and anthropogenic activities on anthropogenic activities on groundwater level. The results of the two methods are shown here. elevated compared with that before the mutation, indicating that the rate of cumulative annual rainfall increase was faster after the mutation (2005-2020). In addition, the slope of the cumulative $W$ (normalized) decreased compared to that before the mutation, meaning that the rate of cumulative $W$ 
(normalized) increase was slower after the mutation. Based on the comparative method of the slope changing ratio of cumulative quantity, the contribution rate of rainfall to $W$ was $21.51 \%$, and that of $Q_{G E}$ to $W$ was $78.49 \%$. The contribution rate of anthropogenic activities was greater than that of climate change.

According to Table 5, the elastic coefficient $\left(\varepsilon_{R}\right)$ of $W$ to the annual rainfall was 1.50 , indicating that there was a $15 \%$ change in $W$ if the annual rainfall changed by $10 \%$. The average annual rainfall after the mutation was reduced by $6.62 \%$ compared to that before the mutation; thus, the corresponding change in $W$ based on $\varepsilon_{R}$ after the mutation should have been $-0.07 \mathrm{~m}$. However, according to the statistics of the monitoring data, the actual change in $W(\Delta W)$ before and after the mutation was -0.33 m. By using the elastic coefficient method, the contribution rates of climate change and anthropogenic activities to $W$ were calculated to be $22.64 \%$ and $77.36 \%$, respectively.

According to the results of these two methods, the relative difference in the calculation results of the two methods was less than 5\% (Table 6), and anthropogenic activities had a greater influence on the variation in groundwater level, while the influence of climate change was relatively small. The quantitative results were consistent with the qualitative analysis. Therefore, the averages of the calculated results based on the two methods were determined to be the quantitative results, that is, the contribution rate of climate change to $W$ was $22.08 \%$, and the contribution rate of anthropogenic activities was $77.92 \%$.

\section{Protection and management of groundwater}

As shown in Fig. 3, the $W$ values in the study area were always negative, and the groundwater level continued to decrease until recent years. The contribution rate of climate change to $W$ was only $22.08 \%$, which is much less than the contribution rate of anthropogenic activities to $W(77.93 \%)$. The positive influence of increased rainfall on groundwater recharge was not enough to offset the negative influence of anthropogenic exploitation.

According to Table 3 and Fig. 5, when $Q_{G E}$ was greater than 0.4 billion $\mathrm{m}^{3}$, the $W$ values in the normal and dry years were always negative, and the groundwater level decreased. Under the current mining conditions, the recharge of groundwater in normal and dry years is insufficient, while the $Q_{G E}$ is excessive, which is not conducive to the sustainable development of the groundwater environment. 
Climate is uncontrollable and has a relatively slight influence on groundwater. According to this study,

with the aid of the positive guidance of anthropogenic activities, groundwater exploitation can be appropriately reduced, unconventional water sources can be developed and utilized to relieve the pressure on groundwater, and additional measures can be taken to scientifically protect and manage groundwater.

\section{Conclusions}

In this paper, $W$ was selected as the analysis factor of groundwater, and rainfall and $Q_{G E}$ were selected as the factors of climate change and anthropogenic activities that influence groundwater, respectively. Based on the analysis of the changes in rainfall, $Q_{G E}$ and $W$, the influence of climate change and anthropogenic activities on groundwater was qualitatively analyzed according to different years and conditions. The quantitative assessment was realized by the $M-K$ mutation test, comparative method of the slope changing ratio of cumulative quantity and elastic coefficient method. The main conclusions were as follows:

(1) The annual rainfall in the study area showed an upward trend, but $W$ was always negative, and the groundwater level in the study area showed a downward trend. Through the comparative analysis of the $W$ under different conditions, there was a positive correlation between the annual rainfall and $W$ and a negative correlation between $Q_{G E}$ and $W$, and the positive influence of rainfall on $W$ was less than the negative influence of $Q_{G E}$.

(2) According to the $M-K$ mutation test and cumulative anomaly method, 2004 was determined as the mutation year. The period from 1996-2004 was defined as the period before the mutation, and the period 2005-2020 was defined as the period after the mutation.

(3) The quantitative assessment of the influence of climate change and anthropogenic activities was performed according to the comparative method of the slope changing ratio of cumulative quantity and the elastic coefficient method, and the relative differences in the results of the two methods were less than $5 \%$. The contribution rate of climate change to the groundwater level was $22.08 \%$, and the contribution rate of anthropogenic activities was $77.92 \%$. The negative influence of anthropogenic activities on $W$ was much greater than that of climate change, which was consistent with the qualitative analysis.

(4) Under the current mining conditions, $W$ was negative in general, the recharge of groundwater in normal and dry years was insufficient, and $Q_{G E}$ was excessive. According to this study, climate 
change is uncontrollable and has a relatively slight influence on groundwater; however, anthropogenic activities can be guided positively to scientifically protect and manage groundwater, such as appropriately reducing groundwater exploitation and utilizing unconventional water sources.

Acknowledgements This research was financially supported by the Basic Scientific Research Foundation Special Project of the China Institute of Water Resources and Hydropower Research (no. MK2021J07) and the National Natural Science Foundation of China (no. 42072291).

\section{References}

Acharyya, Achiransu (2014) Groundwater, Climate Change and Sustainable Well Being of the Poor: Policy Options for South Asia, China and Africa. Procedia - Social and Behavioral Sciences 157:226-235. https://doi.org/10.1016/j.sbspro.2014.11.025

China Geological survey (2018) Handbook of Hydrogeology (2th). Geological Publishing House, Beijing, pp 692-694.

Cui Y, Liao Z, Wei Y, Xu X, Song Y., Liu H (2020) The Response of Groundwater Level to Climate Change and Human Activities in Baotou City, China. Water 12(4):1078. https://doi.org/10.3390/w12041078

Fang C, Sun S, Jia S, Li Y (2019) Groundwater Level Analysis Using Regional Kendall Test for Trend with Spatial Autocorrelation. Ground water 57(2). https://doi.org/10.1111/gwat.12800

Fei Y, Miao J, Zhang Z, Chen Z, Song H, Yang M (2009) Analysis on Evolution of Groundwater Depression Cones and Its Leading Factors in North China Plain. Resources Science. 31(03):394-399. https://doi.org/10.6041/j.issn.1000-1298.2017.09.025 (in Chinses)

Gemitzi A, Stefanopoulos K (2011) Evaluation of the effects of climate and man intervention on ground waters and their dependent ecosystems using time series analysis. Journal of Hydrology. 403 (1-2):130-140. https://doi.org/10.1016/j.jhydrol.2011.04.002

Guo X, Chen X, Chen Y, Wang Y (2016) Impacts of climate variability and human activities on runoff of Minjiang River Basin. Science of Soil and Water Conservation 14(02):88-94. https://doi.org/10.16843/j.sswc.2016.02.012(in Chinses)

He S, Wu J (2019a) Hydrogeochemical characteristics, groundwater quality and health risks from hexavalent chromium and nitrate in groundwater of Huanhe Formation in Wuqi County, northwest China. Expo Health 11(2):125-137. https://doi.org/10.1007/s12403-018-0289-7

He S, Wu J (2019b) Relationships of groundwater quality and associated health risks with land use/land cover patterns: a case study in a loess area, northwest China. Hum Ecol Risk Assess 25(1-2):354-373. https://doi.org/10.1080/10807039.2019.1570463

He S, Li P, Wu J, Elumalai V, Adimalla N (2020) Groundwater quality under land use/land cover changes: A temporal study from 2005 to 2015 in Xi'an, northwest China. Hum Ecol Risk 
Assess 26(10):2771-2797. https://dx.doi.org/10.1080/10807039.2019.1684186

He X, Li P (2020) Surface water pollution in the middle Chinese Loess Plateau with special focus on hexavalent chromium $\left(\mathrm{Cr}^{6+}\right)$ : occurrence, sources and health risks. Expo Health 12(3):385-401. https://doi.org/10.1007/s12403-020-00344-x

Hotta N, Tanaka N, Sawano S, Koichiro Kuraji, Katsushige Shiraki, Masakazu Suzuki (2010) Changes in groundwater level dynamics after low-impact forest harvesting in steep, small $\begin{array}{llll}\text { watersheds. Journal of Hydrology } & \text { 120-131. }\end{array}$ https://doi.org/10.1016/j.jhydrol.2010.02.008

Jin J, Zhao Y, Liu D, Chen Y, Ding H (2020) Quantitative evaluation of the groundwater environment: A case study in Tongliao, China. Human and Ecological Risk Assessment.26(9):2367-2389. https://doi.org/10.1080/10807039.2020.1761245

Kearns TJ, Wang G, Bao Y, Jiang J, Lee D (2015) Current Land Subsidence and Groundwater Level Changes in the Houston Metropolitan Area (2005-2012). Journal of Surveying Engineering.141(4):05015002. https://doi.org/10.1061/(ASCE)SU.1943-5428.0000147

Khan R, Indhulekha K, Mawale Y K, Dewangan R, Shekhar S, Dwivedi CS, Singh VK, Jhariya DC (2020) Impact of anthropogenic activities on groundwater quality and quantity in Raipur City, Chhattisgarh, India. IOP Conference Series: Earth and Environmental Science 597(1):012006. https://doi.org/10.1088/1755-1315/597/1/012006

Li E (2016) Response of Runoff and Sediment to Climate and Human Activities in the Huangfuchuan Watershed of the Middle Reaches of the Yellow River. Ph. D. Thesis, Northwest A\&F University, Yangling. (in Chinses)

Li H, Liu Y, Wang W, Pang M (2021) Assessing the Impact of Meteorological Factors on Streamflow in Aksu River. Journal of Irrigation and Drainage. 40(1):115-122. https://doi.org/10.13522/j.cnki.ggps.2020287 (in Chinses)

Li M, Xiao C, Liang X, Hu B (2018a) Analysis on the dynamic characteristics of groundwater and driving factors within changing environment. Water Resources and Hydropower Engineering 49(11):1-7. https://doi.org/10.13928/j.cnki.wrahe.2018.11.001 (in Chinses)

Li P (2014). Research on Groundwater Environment under Human Interferences: A Case Study from Weining Plain, Northwest China. Ph. D. Thesis, Chang'an University, Xi'an. (in Chinses)

Li P, He S, Yang N, Xiang G (2018b) Groundwater quality assessment for domestic and agricultural purposes in Yan'an City, northwest China: implications to sustainable groundwater quality management on the Loess Plateau. Environ Earth Sci 77(23):775. https://doi.org/10.1007/s12665-018-7968-3

Li P, He X, Li Y, Xiang G (2019) Occurrence and health implication of fluoride in groundwater of loess aquifer in the Chinese Loess Plateau: a case study of Tongchuan, northwest China. Expo Health 11(2):95-107. https://doi.org/10.1007/s12403-018-0278-x

Liao Z, Long Y, Liu H, Song Y, Guo Z, Wei Y (2014) Influence of Climate Change and Human Activities on Groundwater Level in Baotou City. Arid Zone Research. 31(01):138-143. 
https://doi.org/10.13866/j.azr.2014.01.026 (in Chinses)

Liu J, Yang P, Kan J, Gao Y (2019a) Dynamic Trend and Driving Factors of Groundwater in Shawan Irrigated District under Changing Environment. Water Saving Irrigation. (03):53-58. https://doi.org/10.3969/j.issn.1007-4929.2019.03.012 (in Chinses)

Liu Y, Yuan F, Wang Z, Wu J, Zheng X, Yin H, Guan D (2019b) Characteristics of climate change in Changbai Mountain ecological functional area, Northeast China. Chinese Journal of Applied Ecology 30(5):1503-1512. https://doi.org/10.13287/j.1001-9332.201905.006

Malakar P, Mukherjee A, Bhanja S N, Ganguly A R, Chattopadhyay S (2021) Three decades of depth-dependent groundwater response to climate variability and human regime in the transboundary Indus-Ganges-Brahmaputra-Meghna mega river basin aquifers. Advances in Water Resources 149:103856. https://doi.org/10.1016/J.ADVWATRES.2021.103856

Ren X, Li P, He X, Su F, Elumalai V (2021) Hydrogeochemical processes affecting groundwater chemistry in the central part of the Guanzhong Basin, China. Arch Environ Contam Toxicol 80(1):74-91. https://doi.org/10.1007/s00244-020-00772-5

Sankarasubramanian A, Vogel R M, Limbrunner J F (2001) Climate elasticity of streamflow in the United States. Water Resources Research 37(6):1771-1781. https://doi.org/10.1029/2000WR900330

Shi J, Li G, Liang X, Chen Z, Shao J, Song X (2014) Evolution Mechanism and Control of Groundwater in the North China Plain. Acta Geoscientica Sinica. 35(05):527-534. https://doi.org/10.3975/cagsb.2014.05.01 (in Chinses)

Su Z, Wu J, He X, Elumalai V (2020) Temporal changes of groundwater quality within the groundwater depression cone and prediction of confined groundwater salinity using Grey Markov model in Yinchuan area of northwest China. Expo Health 12(3):447-468. https://doi.org/10.1007/s12403-020-00355-8

Wang D, Wu J, Wang Y, Ji Y (2020) Finding high-quality groundwater resources to reduce the hydatidosis incidence in the Shiqu County of Sichuan Province, China: analysis, assessment, and management. Expo Health 12(2):307-322. https://doi.org/10.1007/s12403-019-00314-y

Wang H, Wang J, Qin D, Jia Y (2006) Theory and methodology of water resources assessment based on dualistic water cycle model. Journal of Hydraulic Engineering 37(12):1496-1502. https://doi.org/10.3321/j.issn:0559-9350.2006.12.015 (in Chinses)

Wang J, Zhang G, Mu H, Yan M (2011) Quantitative valuation and validation of the influence degree of human activities on shallow groundwater. Journal of Hydraulic Engineering 42(12):1445-1451. https://doi.org/10.13243/j.cnki.slxb.2011.12.002 (in Chinses)

Wang S, Yan Y, Yan M, Zhao X (2012) Contributions of Precipitation and Human Activities to the Runoff Change of the Huangfuchuan Drainage Basin: Application of Comparative Method of the Slope Changing Ratio of Cumulative Quantity. Acta Geographica Sinca 67(03):388-397. https://doi.org/10.11821/xb201203010 (in Chinses)

Wang X, You X, Yang Z, Zhang Y, Xie W (2019) Spatio-temporal changes of precipitation in 
Chengdu from 1980 to 2016. Science of Soil and water conservation based on Mann-Kendall test and information entropy. Science of Soil and Water Conservation 17(4):26-33. https://doi.org/10.16843/j.sswc.2019.04.004

Wei M, Wu J, Li W, Zhang Q, Su F, Wang Y (2021) Groundwater geochemistry and its impacts on groundwater arsenic enrichment, variation, and health risks in Yongning County, Yinchuan Plain of northwest China. Expo Health. https://doi.org/10.1007/s12403-021-00391-y

Wei R, Xiao C, Fang Z (2016) Trends Mutation Nodes of Groundwater Dynamic in Jiansanjiang Area of Heilongjiang Province. Journal of Jilin University (Earth Science Edition) 46(1):202-210. https://doi.org/10.13278/j.cnki.jjuese.201601204 (in Chinses)

Wilopo W, Putra D.P.E, Hendrayana H, Hendrayana H (2021) Impacts of precipitation, land use change and urban wastewater on groundwater level fluctuation in the Yogyakarta-Sleman Groundwater Basin, Indonesia. Environmental Monitoring and Assessment 193(2). https://doi.org/10.1007/S10661-021-08863-Z

Wu J, Zhang Y, Zhou H (2020) Groundwater chemistry and groundwater quality index incorporating health risk weighting in Dingbian County, Ordos basin of northwest China. Geochemistry 80(4):125607. https://doi.org/10.1016/j.chemer.2020.125607

Wu J, Zhou H, He S, Zhang Y (2019) Comprehensive understanding of groundwater quality for domestic and agricultural purposes in terms of health risks in a coal mine area of the Ordos basin, north of the Chinese Loess Plateau. Environ Earth Sci 78(15):446. https://doi.org/10.1007/s12665-019-8471-1

Yihdego Y, Danis C, Paffard A (2017a) Why is the Groundwater Level Rising? A Case Study Using HARTT to Simulate Groundwater Level Dynamic. Water Environment Research 89 (12):2142-2152. https://doi.org/10.2175/106143017X14839994523785

Yihdego Y, Reta G, Becht R (2017b) Human impact assessment through a transient numerical modeling on the UNESCO World Heritage Site, Lake Naivasha, Kenya.Environmental Earth Sciences 76:9. https://doi.org/10.1007/s12665-016-6301-2

Zhao Y, Wang W, Zhang D, Liang S (2019) Slope Change Analysis Method of Cumulative Quantity and Its Application in Runoff Change Attribution. Water Resources and Power. 37(10):17-20. (in Chinese)

Zhu Y, Zhang S, Zhao S, Sun B, Liu Y, Zhang Y (2017) Impacts of Climate Change and Human Activities on Changes of Groundwater Level. Transactions of the Chinese Society for Agricultural Machinery 48(9): 199-205. https://doi.org/10.6041/j.issn.1000-1298.2017.09.025 (in Chinese) 
Fig. 1 Location of the study area and distribution of the monitoring wells

Fig. 2 Box chart of monthly rainfall (1996-2020)

Fig. 3 Changes in annual rainfall, $Q_{G E}, W$ and $H$ (1996-2020). For convenience, the order of magnitude of the annual rainfall was appropriately adjusted, and the $Q_{G E}$ values were adjusted to negative values by multiplying by -1 due to the negative influence of groundwater exploitation on the groundwater level.

Fig. 4 Comparison of $W$ and annual rainfall under exploitation conditions $A(\mathbf{a})$ and $B(\mathbf{b})$

Fig. 5 Comparison of $W$ and $Q_{G E}$ under rainfall conditions $A^{\prime}(\mathbf{a}), B^{\prime}(\mathbf{b})$ and $C^{\prime}(\mathbf{c})$

Fig. 6 Groundwater flow field and the distribution of the selected monitoring wells

Fig. 7 Changes in the monthly rainfall and $W_{m o n}$ during wet years (a and $\left.\mathbf{b}\right)$, normal years (c and $\left.\mathbf{d}\right)$ and dry years (e and $\mathbf{f})$

Fig. $8 U F$ and $U B$ curves of the annual rainfall (a) and $W$ (b) from 1996 to 2020 based on the $M-K$ mutation test

Fig. 9 Cumulative anomaly curves of the annual rainfall (a) and $W$ (b) from 1996 to 2020 based on the cumulative anomaly method

Fig. 10 Cumulative curves of the annual rainfall (a) and $W(\mathbf{b})$ and their trend lines. $W$ (normalized): The $W$ value has been normalized according to Eq. (3). 
Figures

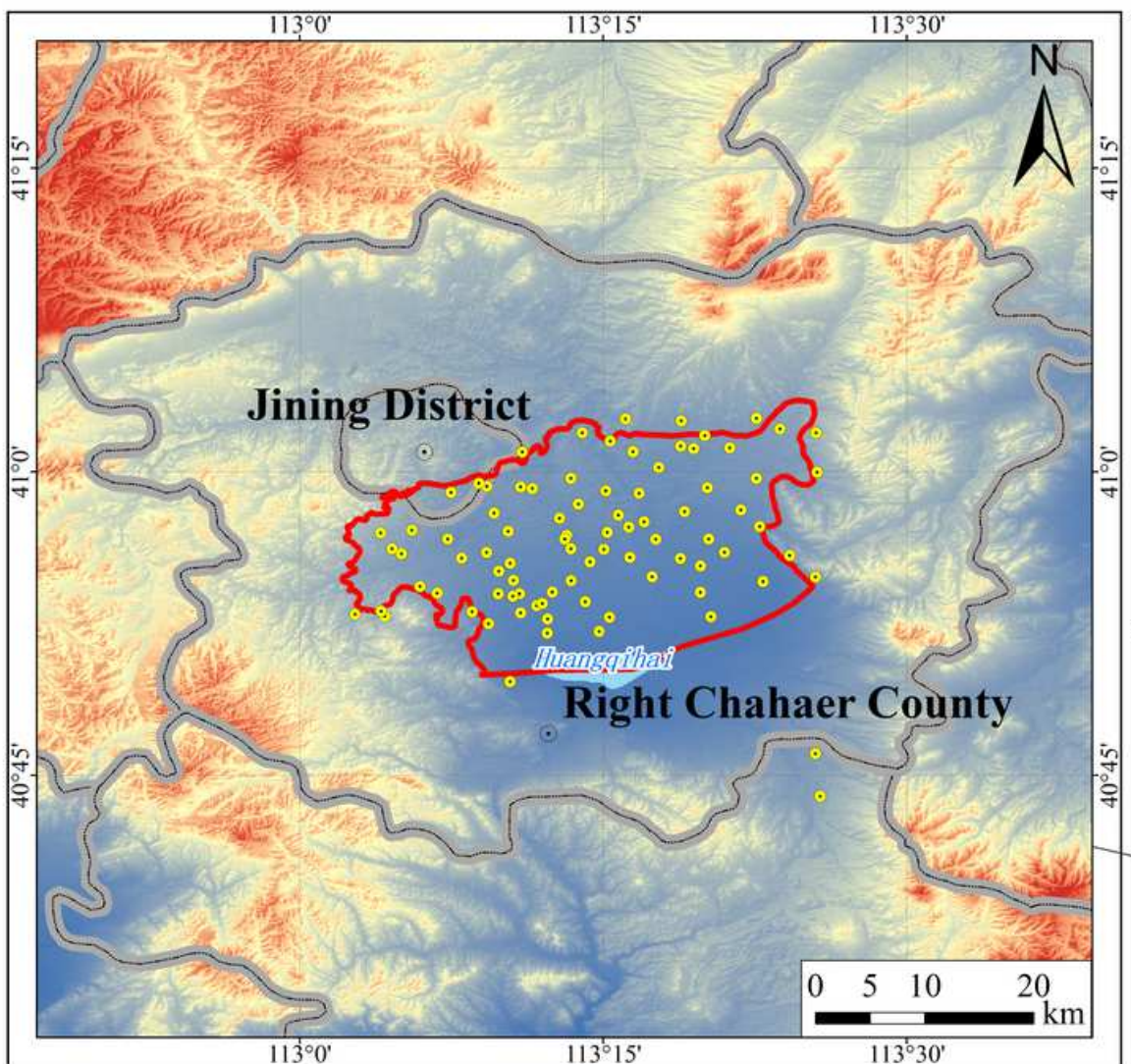

Legend

- Monitoring well on groundwater level

Boundary of the study area

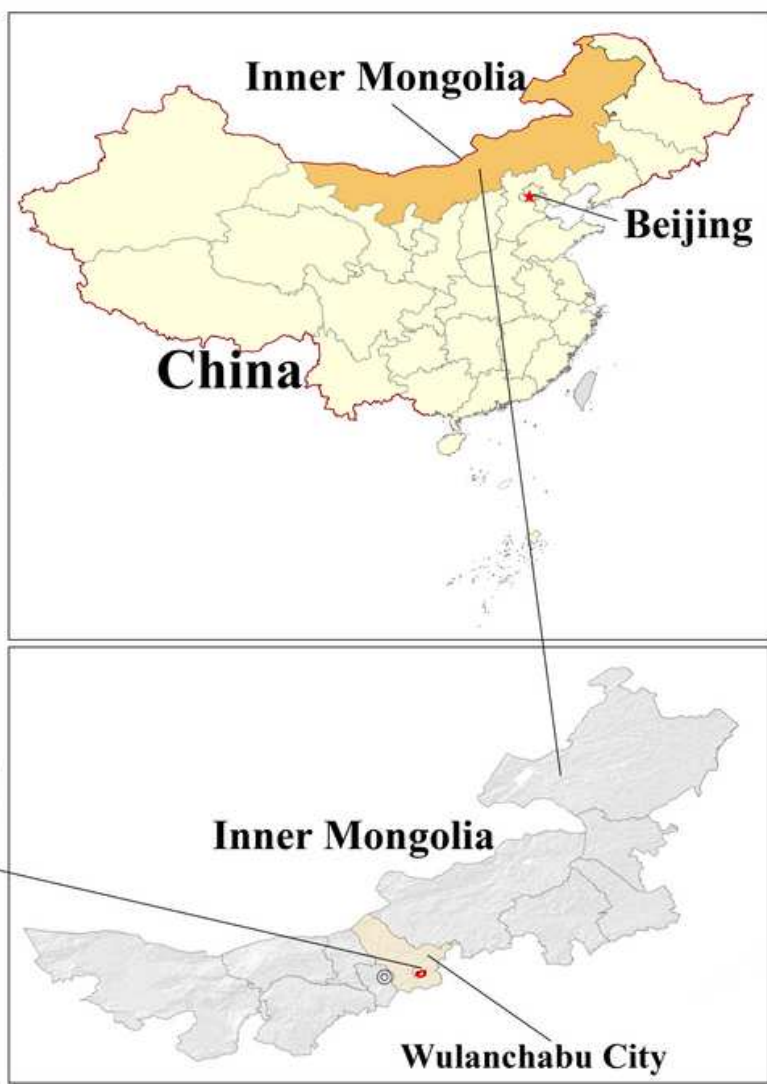

Elevation (m)

Boundary of county

Huangqihai Lake
2124

1240

\section{Figure 1}

Location of the study area and distribution of the monitoring wells 


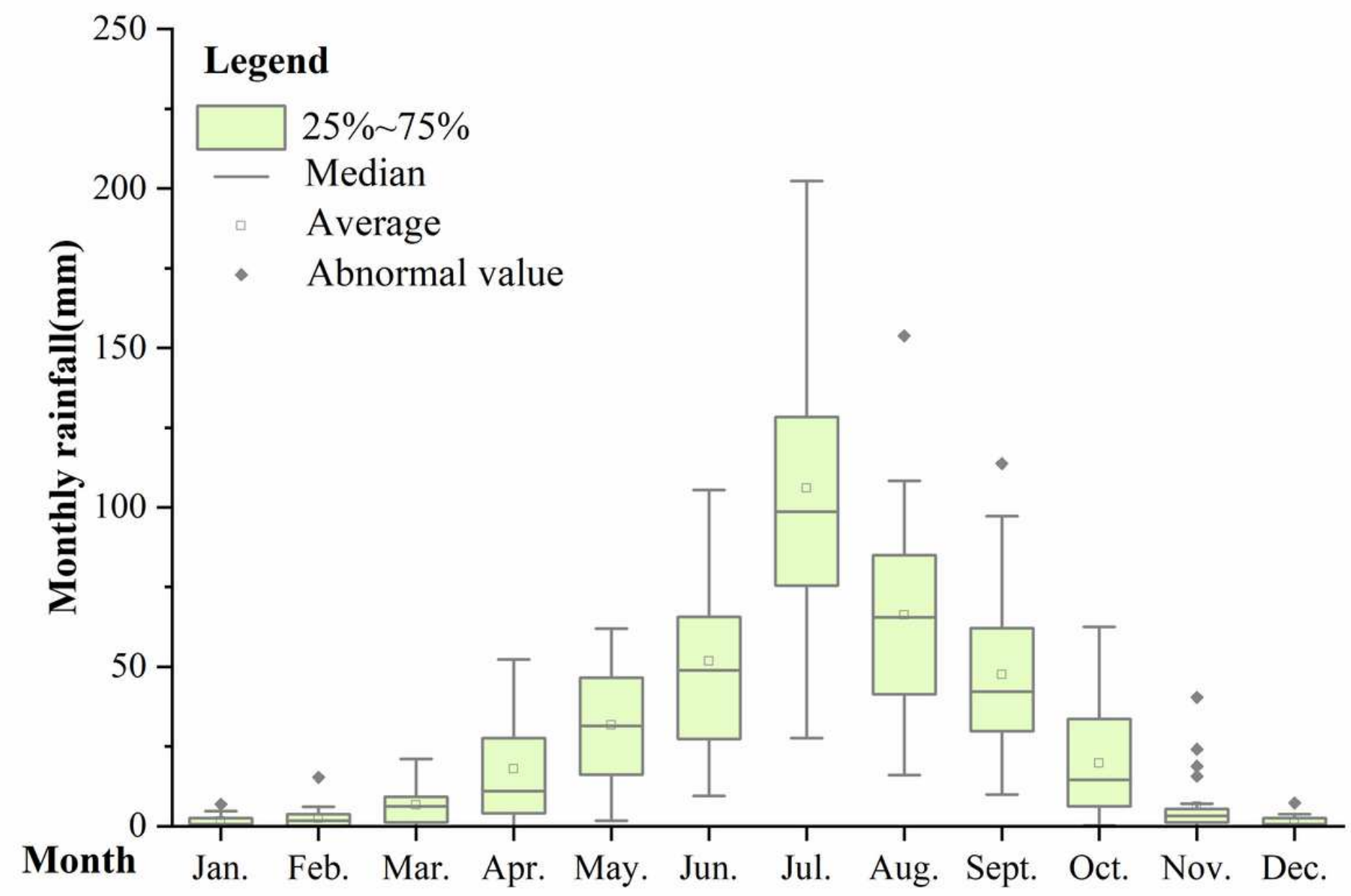

Figure 2

Box chart of monthly rainfall (1996-2020) 


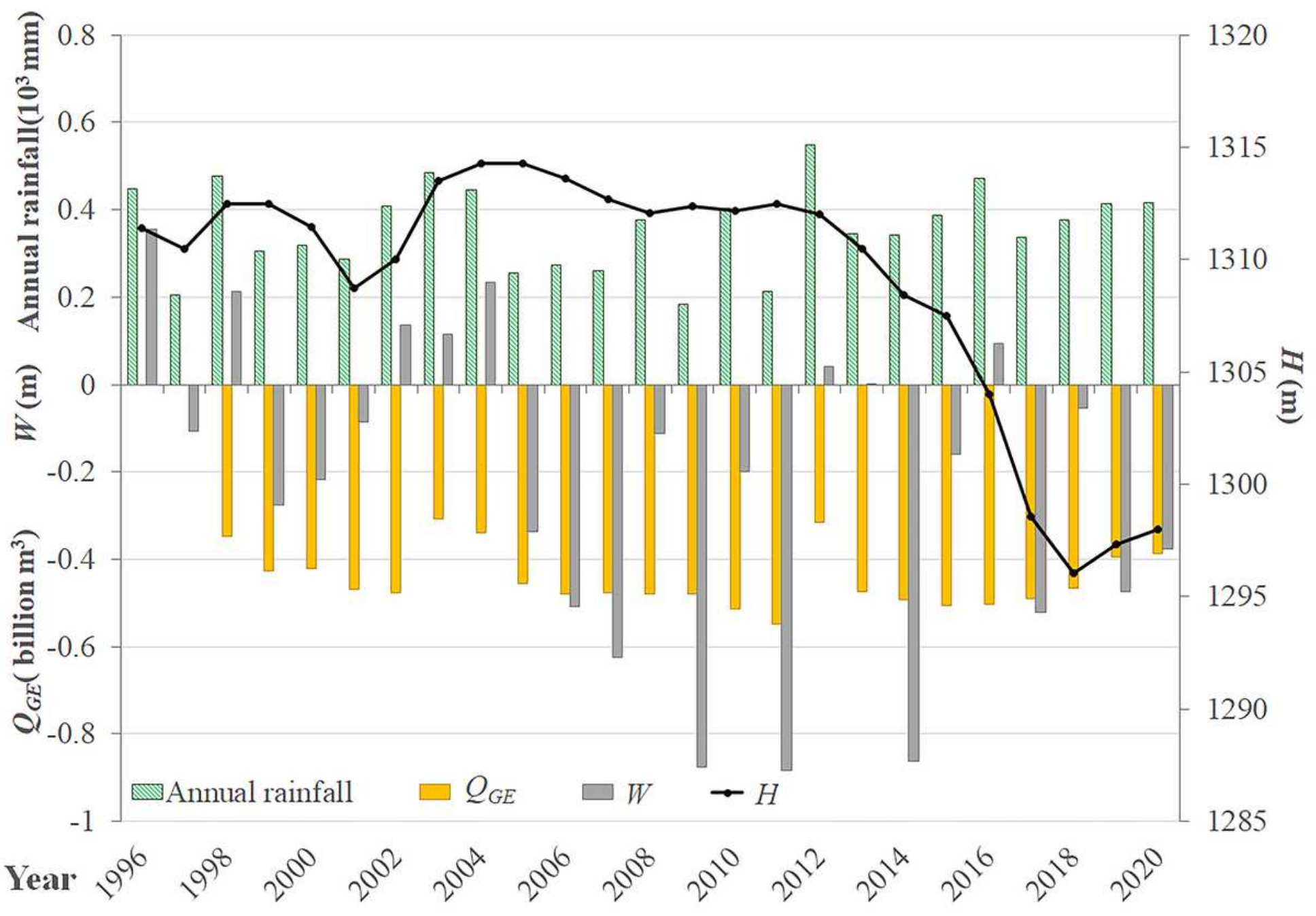

Figure 3

Changes in annual rainfall, QGE, W and $\mathrm{H}$ (1996-2020). For convenience, the order of magnitude of the annual rainfall was appropriately adjusted, and the QGE values were adjusted to negative values by multiplying by -1 due to the negative influence of groundwater exploitation on the groundwater level. 


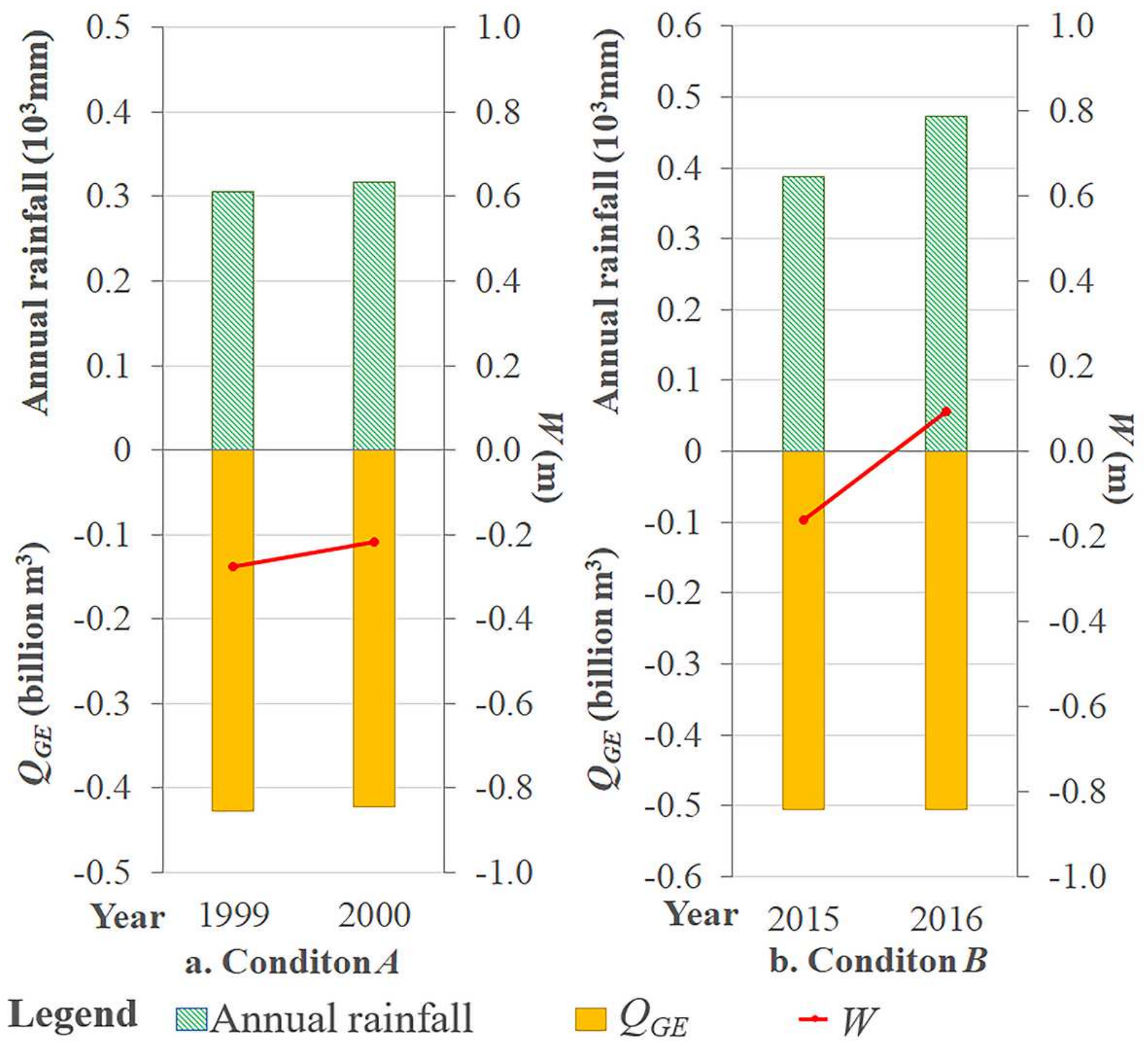

Figure 4

Comparison of $\mathrm{W}$ and annual rainfall under exploitation conditions $\mathrm{A}(\mathrm{a})$ and $\mathrm{B}(\mathrm{b})$ 


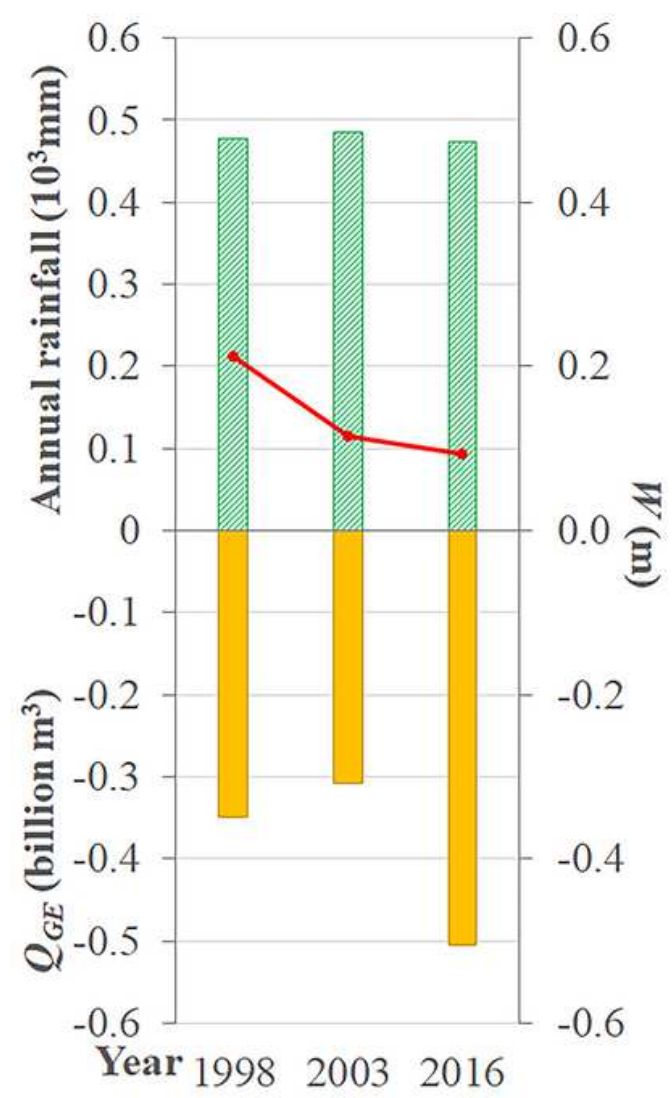

a. Condition $A^{\prime}$

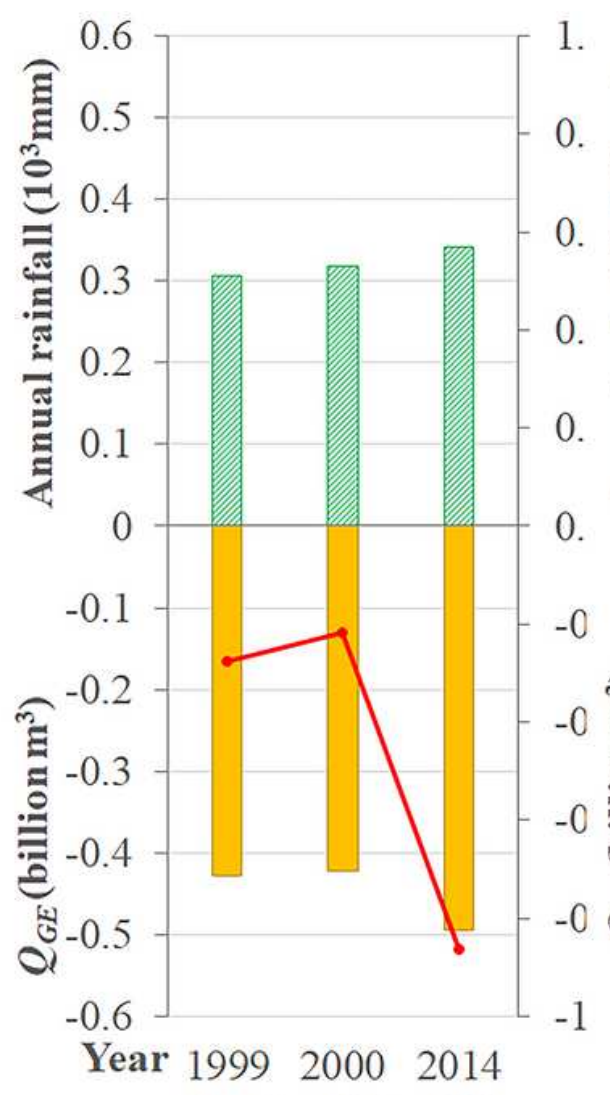

b. Condition $B^{\prime}$

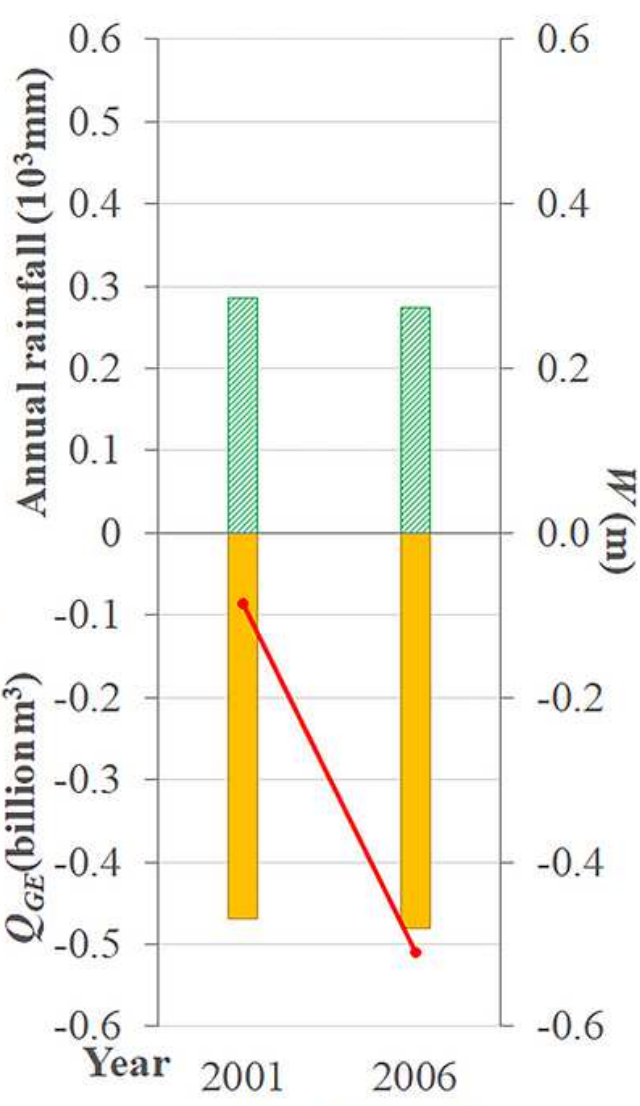

c. Condition $C^{\prime}$

Legend Annual rainfall $\square Q_{G E} \quad-W$

Figure 5

Comparison of W and QGE under rainfall conditions $A^{\prime}(a), B^{\prime}(b)$ and $C^{\prime}(c)$ 


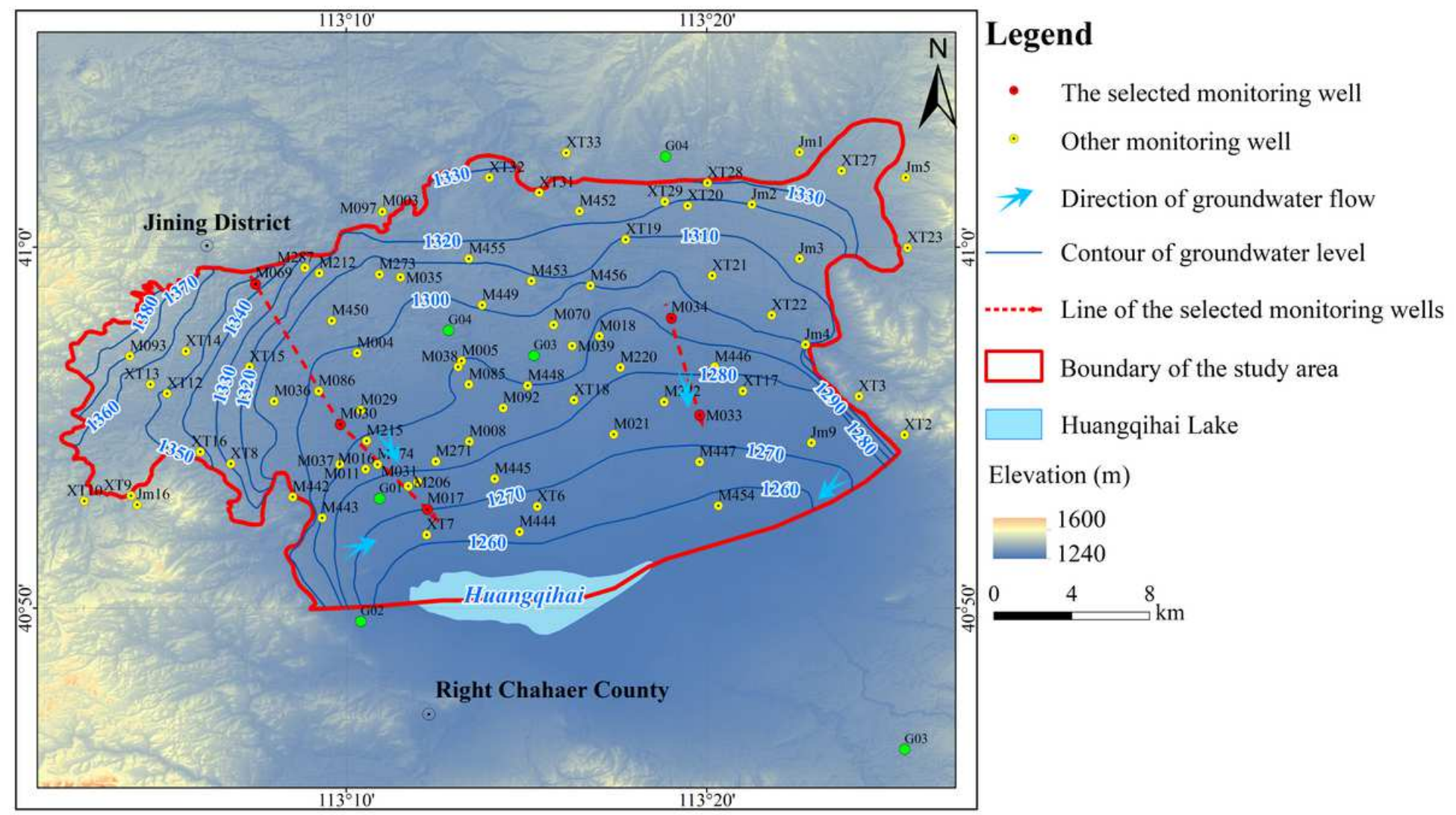

Figure 6

Groundwater flow field and the distribution of the selected monitoring wells 


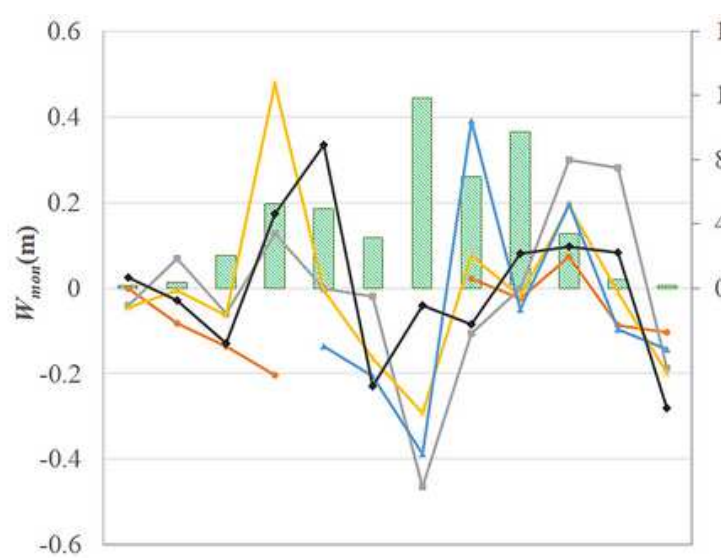

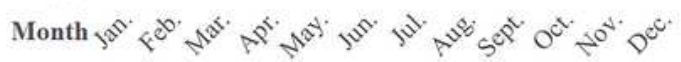
a. Wet year-2003

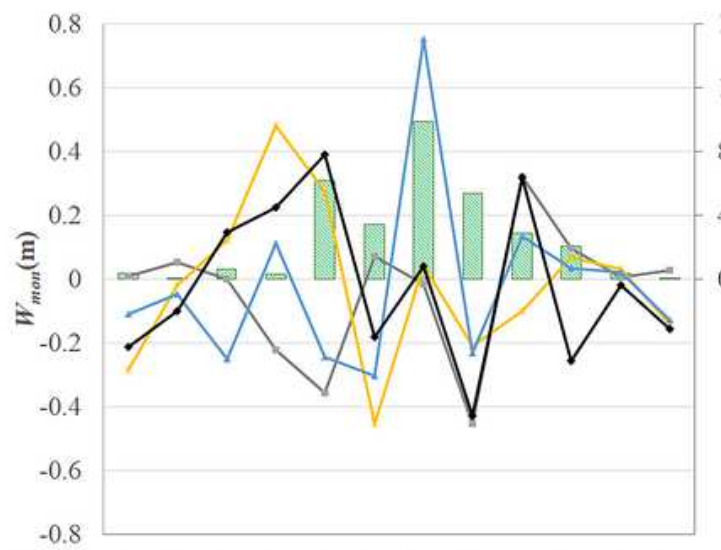

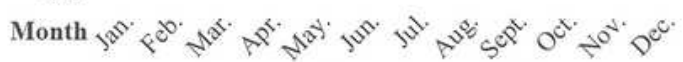
c. Normal year-2000

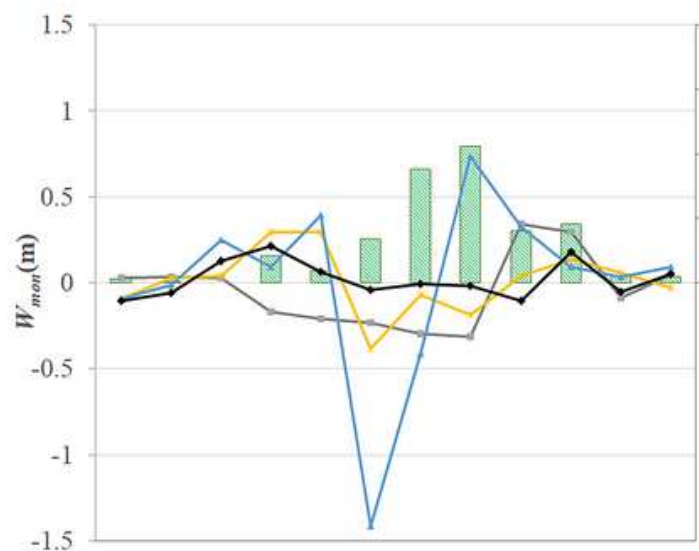

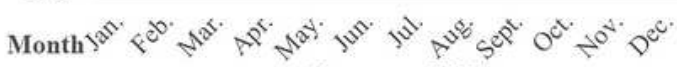
e. Dry year-2001

Legend $\square$ Monthly rainfall $\quad-$ M069 $\quad-$ M030 $\quad-$ M017 $\quad-$ M034 $\quad \rightarrow$ M033

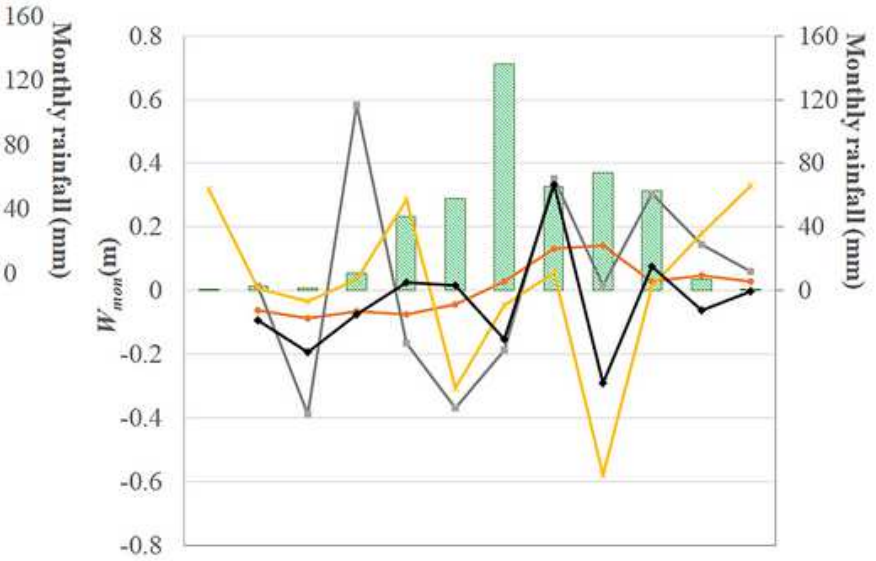

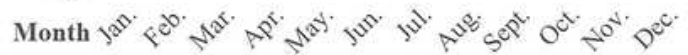

b. Wet year-2016

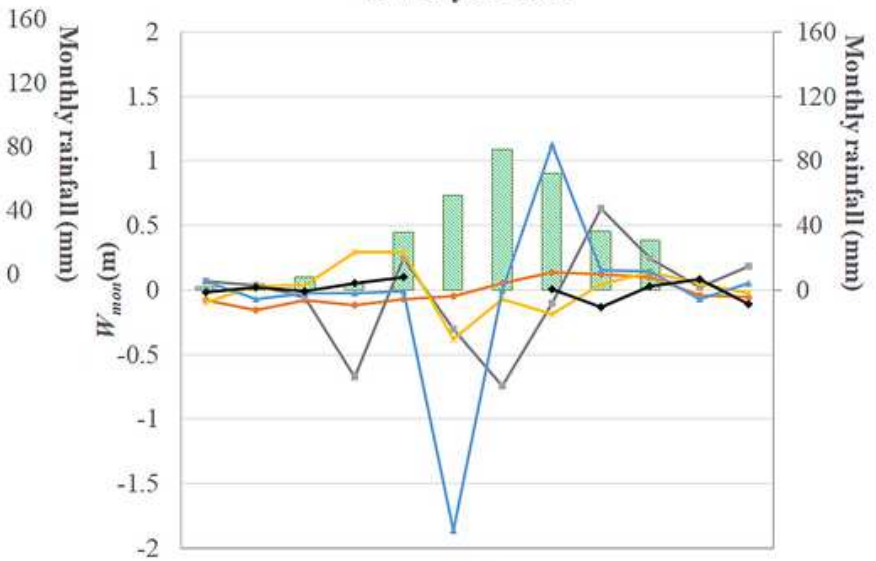

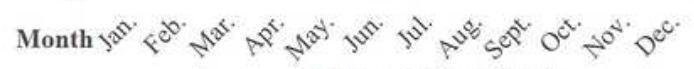

d. Normal year-2014

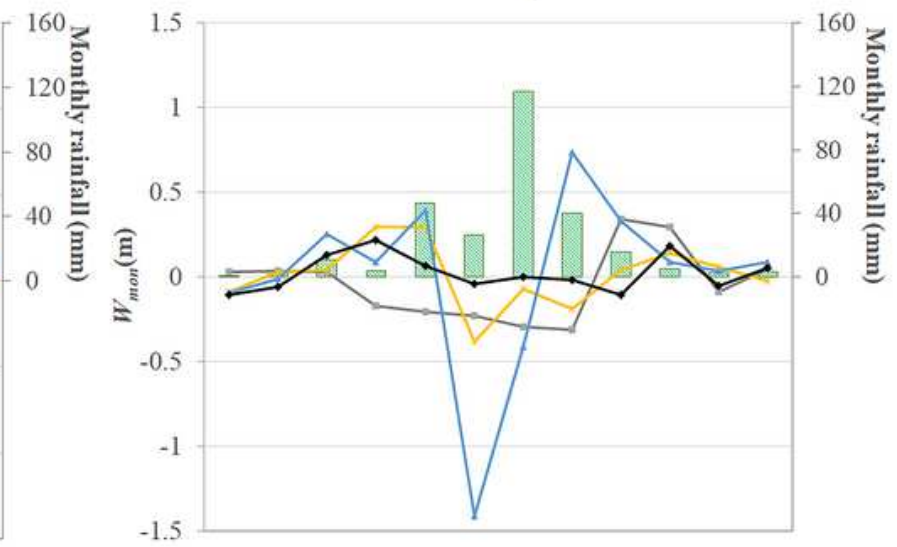

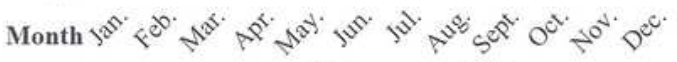

f. Dry year-2006

\section{Figure 7}

Changes in the monthly rainfall and Wmon during wet years ( $a$ and b), normal years (c and d) and dry years (e and $f$ ) 


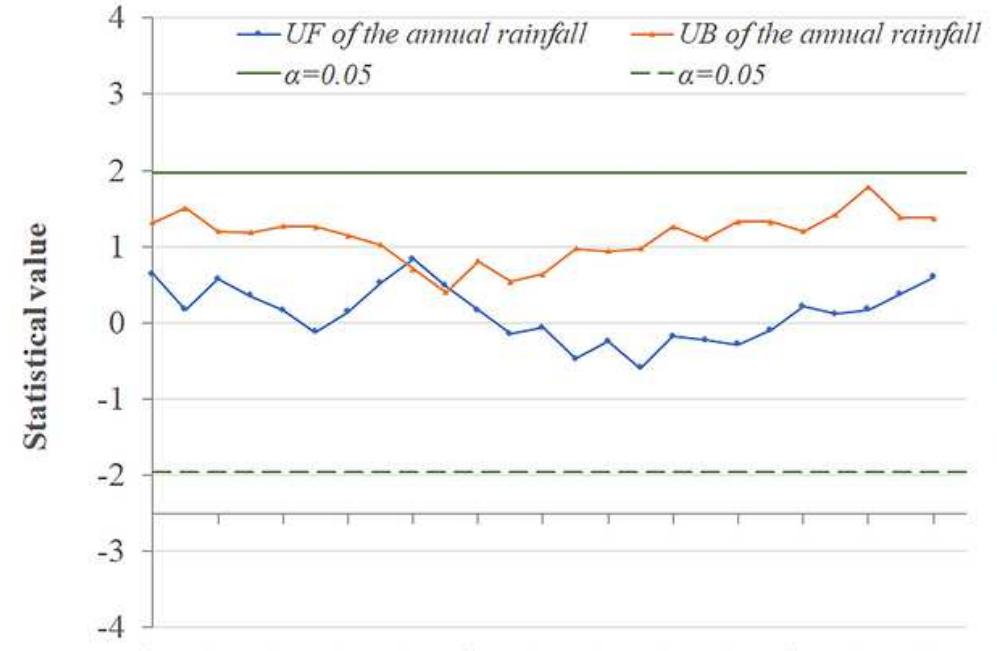

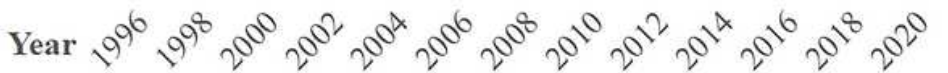

a. Annual rainfall

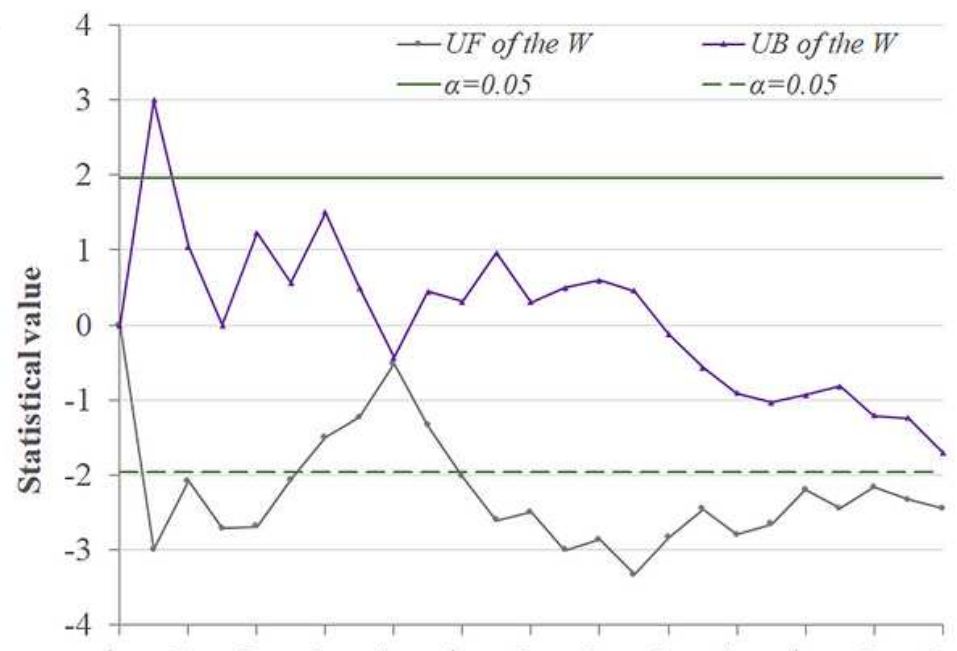

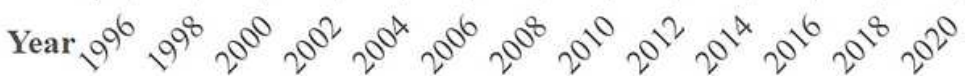
b. $W$

\section{Figure 8}

UF and UB curves of the annual rainfall (a) and W (b) from 1996 to 2020 based on the M-K mutation test

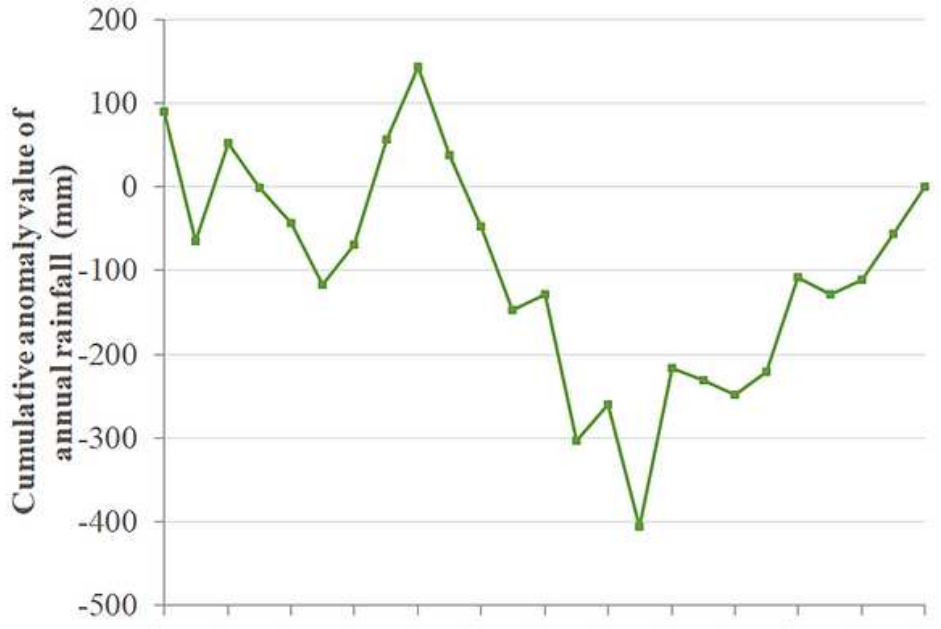

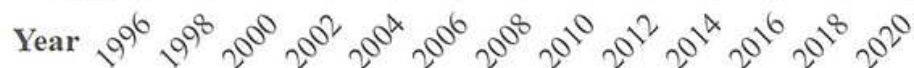
a. Annual rainfall

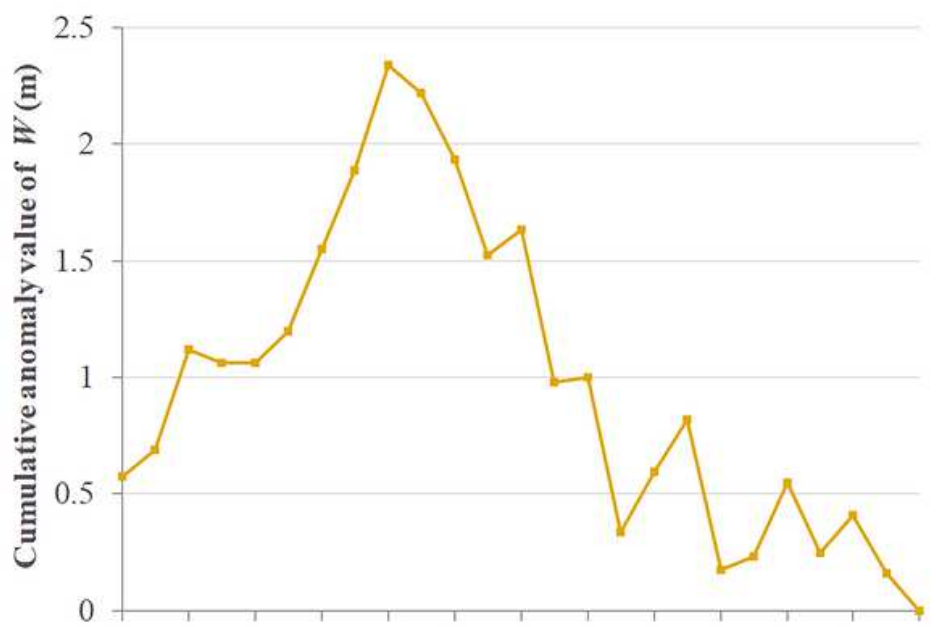

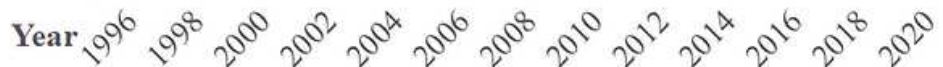

b. $W$

\section{Figure 9}

Cumulative anomaly curves of the annual rainfall (a) and W (b) from 1996 to 2020 based on the cumulative anomaly method 


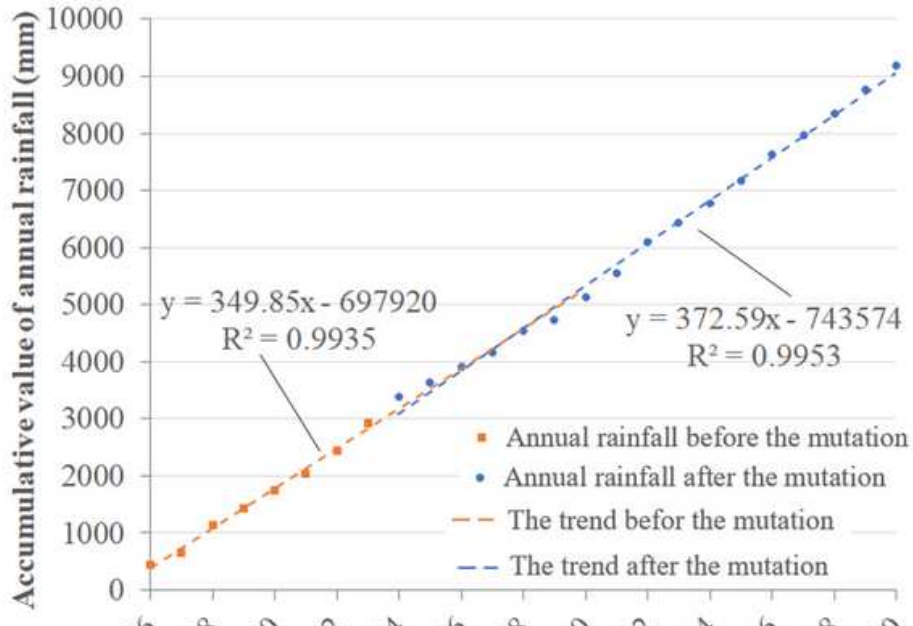

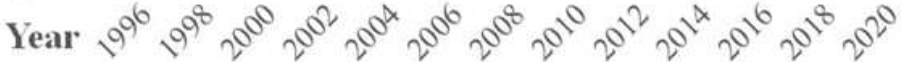

a. Annual rainfall

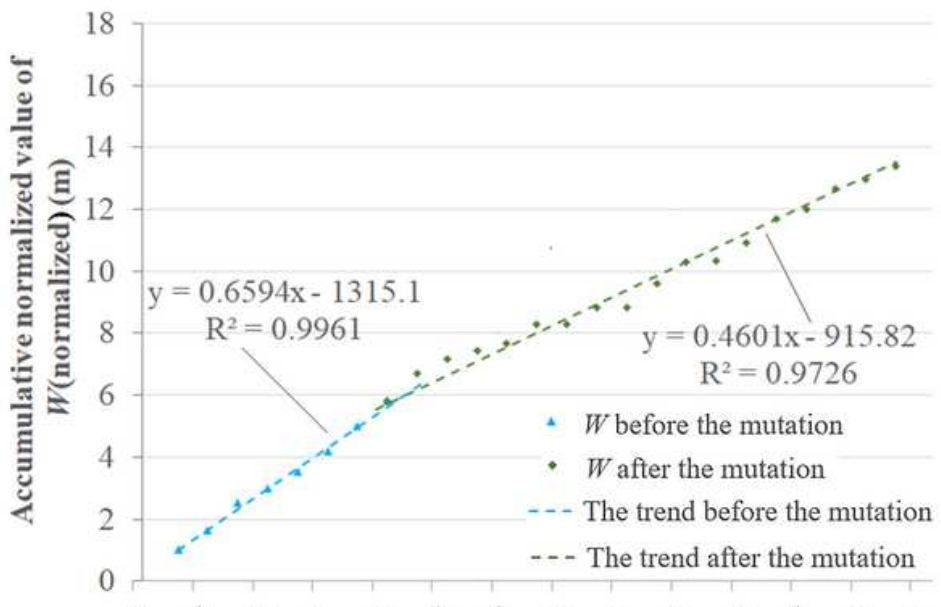

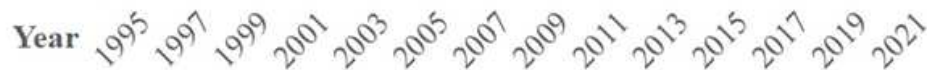
b. $W$ (normalized)

\section{Figure 10}

Cumulative curves of the annual rainfall (a) and W (b) and their trend lines. W (normalized): The W value has been normalized according to Eq. (3).

\section{Supplementary Files}

This is a list of supplementary files associated with this preprint. Click to download.

- Tables.pdf 